\title{
Improving surveillance of the impact of influenza and its prevention in Canada
}

\author{
DAVID S FEDSON, MD
}

\begin{abstract}
DS FEDSON. Improving surveillance of the impact of influenza and its prevention in Canada. Can J Infect Dis 1993;4(5):257-262. The organization of Canada's provincial health care systems and the administrative databases that sustain them provide physicians, epidemiologists and public health officials with unique opportunities to improve surveillance of influenza and its prevention. These databases can be used to measure the impact of influenza on excess mortality, hospitalization and costs to the health care system. They can also be used to study the epidemiology of influenza vaccination practices. Studies using the administrative database for the province of Manitoba have established the epidemiological rationale for hospital-based vaccination and have evaluated the clinical effectiveness of influenza vaccination. As pneumococcal vaccination becomes widespread in Canada, provincial databases should also prove useful in assessing the impact of the pneumococcal infections and their prevention with pneumococcal vaccine.
\end{abstract}

Key Words: Administrative databases, Influenza, Influenza vaccination, Surveillance

\section{Amélioration de la surveillance épidémiologique de l'influenza et sa prévention au Canada}

RÉSUMÉ: L’organisation des systèmes de soins de santé provinciaux au Canada et les bases de données administratives qui les soutiennent procurent aux médecins, aux épidémiologistes et aux autorités sanitaires la possibilité d'améliorer la surveillance épidémiologique de l'influenza et sa prévention. Ces bases de données peuvent être utilisées pour mesurer l'impact de l'influenza sur les taux de mortalité, des hospitalisations et de coûts supportés par les systèmes de soins de santé. Elles peuvent également être utilisées pour l'analyse épidémiologique des mesures de vaccination contre l'influenza. Les études qui utilisent les bases de données administratives de la province du Manitoba ont servi à justifier, au plan épidémiologique, la vaccination dans les hôpitaux et ont mesuré l'efficacité clinique de la vaccination contre l'influenza. À mesure que la vaccination pneumococcique se répand au Canada, les bases de données provinciales devraient également se révéler utiles pour évaluer les répercussions de l'infection à pneumocoque et de sa prévention au moyen d'un vaccin approprié.

Department of Medicine, University of Virginia School of Medicine, Charlottesville, Virgina, USA; and Manitoba Centre for Health Policy and Evaluation, University of Manitoba, Winnipeg, Manitoba

Correspondence and reprints: Dr David S Fedson, Box 494, University of Virginia Health Sciences Center, Charlottesville, VA 22908, USA. Telephone (804) 924-1685/5856, Fax (804) 924-1138 
$\mathrm{I}$ FEBRUARY 1993, PHYSICIANS, EPIDEMIOLOGISTS AND PUB lic health officials gathered at the National Consensus Conference on Influenza to review current systems for the surveillance of influenza and to assess current approaches to its prevention. As a non-Canadian, the conference provided me with the opportunity to reflect on recent experience with influenza vaccination in Canada.

Over the past decade, Canadians have done a remarkable job of implementing programs for influenza vaccination. During the period between 1980 and 1992 , the per capita use of influenza vaccine in Canada increased by $420 \%$ (Figure 1) (1). Approximately $90 \%$ of all doses are now purchased by provincial and territorial health departments for distribution free of charge to physicians and other providers. Those who submit claims are reimbursed for their services. The system works so well that Canada has become one of the leading countries in the world in its use of influenza vaccine. There is every reason to believe that these efforts have been successful in reducing the serious morbidity and mortality of influenza, although by how much is unknown.

Canadians clearly have something important to teach other countries about the prevention of influenza. Nonetheless, they can still do much to improve their assessment of the impact of disease, their understanding of how their vaccination programs are being implemented, and their knowledge of whether these programs are clinically effective. This article suggests four measures that I believe Canadians should undertake to do this (Table 1).

\section{MEASURE THE IMPACT OF INFLUENZA}

One of the most widely used measures of the impact of influenza is the estimate of excess mortality due to pneumonia and influenza $(\mathrm{P}+\mathrm{I})$ during outbreak periods. In the United States, the Centers for Disease Control suggest that excess mortality varies from 10,000 to 40,000 deaths each year (2). There are no comparable figures for Canada, but assuming that experience with the disease in the two countries is similar and that the number of elderly and other high risk Canadians is approximately $10 \%$ of the number in the United States, there are probably 1000 to 4000 excess $\mathrm{P}+\mathrm{I}$ deaths due to influenza in Canada each year. The total number of deaths is certainly much greater because many influenza-associated deaths are recorded as being due to other causes (3). Extrapolations from data in the United States can be useful, but it would be better to have direct estimates based on Canadian experience.

Regarding excess hospital admissions, estimates for the United States are imprecise and too conservative $(4,5)$. Again, there are no figures for Canada, but there can be little doubt that influenza is associated with an increase in hospital admissions; it clearly occurred

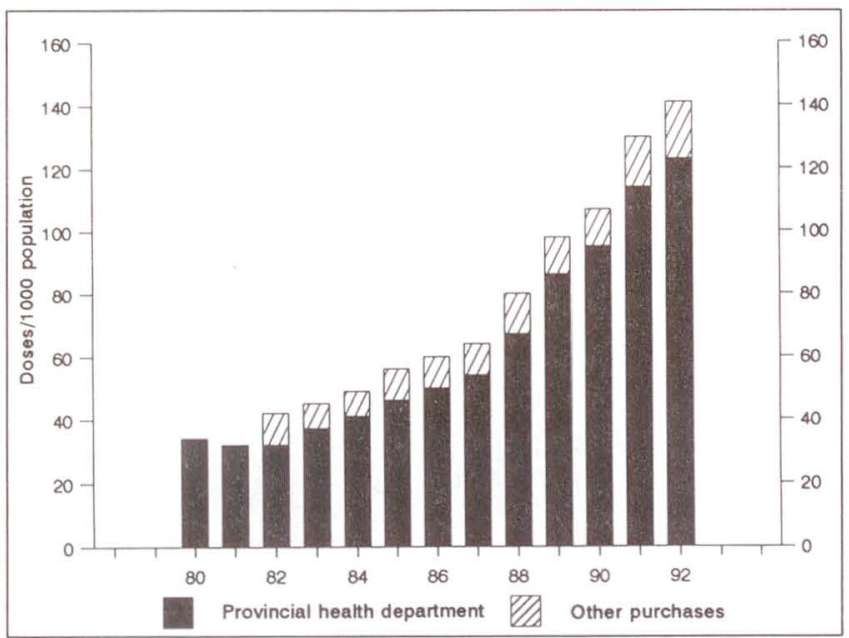

Figure 1) Influenza vaccine distribution in Canada, 1980-92. For 1980 and 1981, data on vaccine purchases by provincial health departments were unavailable. The figure shows only total doses distributed for these two years

\section{TABLE 1 \\ Measures to improve surveillance of the impact of influ- enza and its prevention in Canada}

Measure the impact of influenza on excess mortality. hospitalization, and costs to the health care system

Develop an epidemiology of influenza vaccination practices at the macro- (provincial) and micro- (individual practitioner) level

Document all influenza vaccinations in administrative databases, and use these systems to analyze influenza vaccination practices and vaccine effectiveness and safety

For everything done to enhance influenza vaccination, do the same for pneumococcal vaccination

each year during a recent four-year period in Manitoba (Figure 2). We need to know for Manitoba and for other provinces how many of these admissions constitute excess hospitalization due to influenza.

Finally, there is a need for information on the costs of health care for influenza-related illness. This is especially important for care that is provided by hospitals. Hospital administrators have to stay within global budgets, and thus they need to know the opportunity costs of not being able to provide treatment for some patients because others are admitted with the complications of influenza. In addition, the overall societal costs of influenza should be assessed. In moderately severe outbreaks in the United States these costs may be 10 to 12 billion dollars or more $(6,7)$. Studies in the United States (8) and Canada (9) have shown that influenza vaccination of elderly persons has economic as well as health benefits. It may be that overall cost and cost-effectiveness estimates, rather than measures of the impact of influenza on excess mortality or hospital admissions, will be determining factors in persuading provincial health officials, especially those 


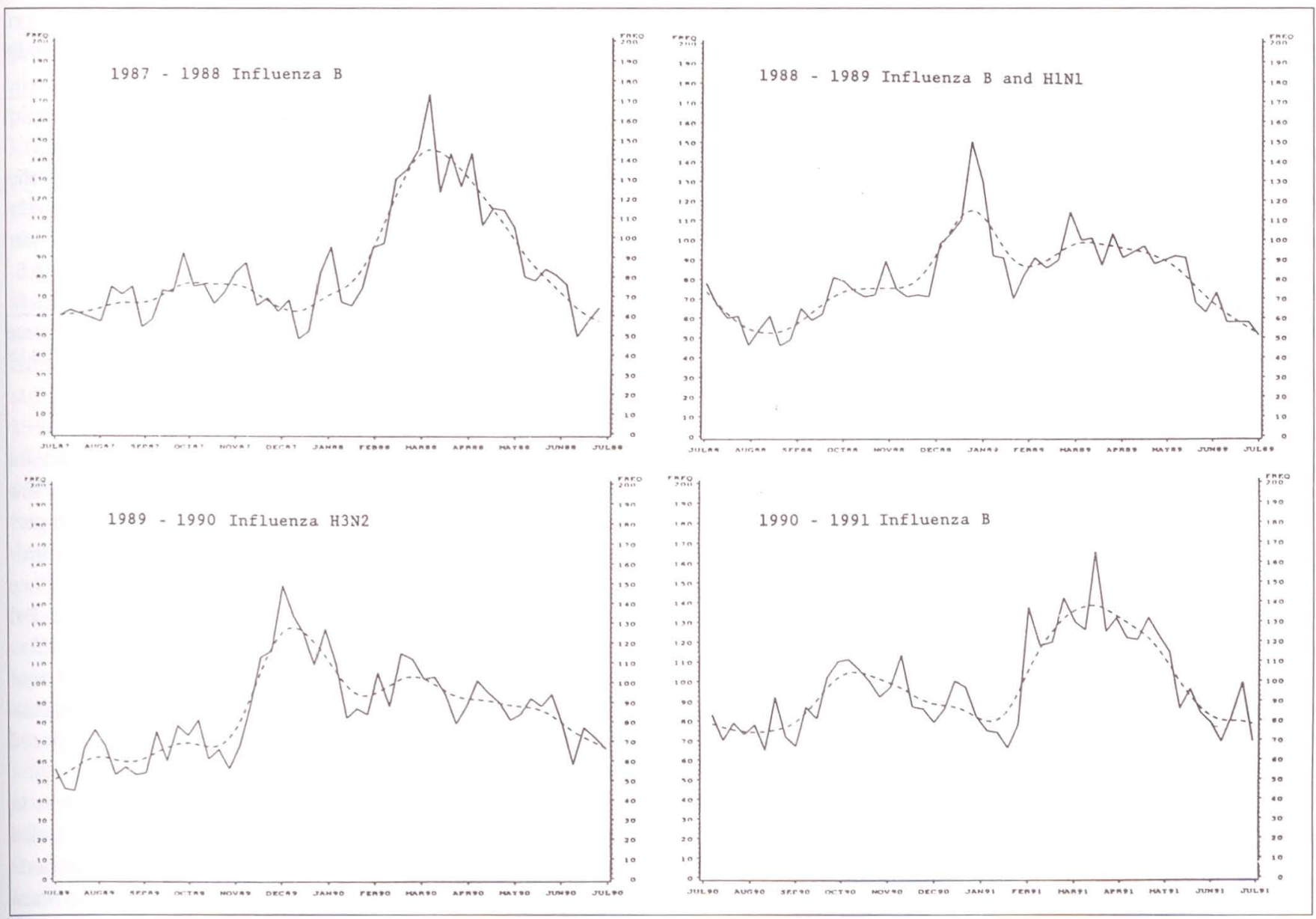

Figure 2) Weekly hospital admissions for pneumonia and influenza (ICD-9-CM 480-487; first-listed discharge diagnosis) in Manitoba during the period 1987-88 to 1990-91

responsible for health care financing, to take a closer look at their programs for influenza prevention to make sure they are reaching those in greatest need.

\section{DEVELOP AN EPIDEMIOLOGY OF IMMUNIZATION PRACTICES}

In recent years, epidemiologists have assessed the impact of influenza in several countries (10). Similarly, virologists in many national influenza centres and in the three World Health Organization (wHo) Collaborating Centres for Influenza monitor the antigenic drift and shift of influenza virus isolates in order to provide information for the wHO experts who determine the composition of each year's influenza vaccine. Given widespread efforts to monitor the disease and its causative agent, it is remarkable that so little has been done to monitor the use of the vaccine that can prevent the disease. I believe that if we are serious about our goal of preventing the morbidity and mortality of influenza, we need to develop an epidemiology of influenza immunization practices that is every bit as detailed as our understanding of the epidemiology of the disease and its virus.

Preliminary information has been presented recently on variations in influenza vaccine distribution in 11 developed countries (11). These findings constitute the beginnings of what might be called the macroepidemiology of influenza immunization practices. They reveal a surprising threefold (ie, 300\%) difference in the per capita distribution of influenza vaccine between countries. Some of these differences seem to be due to differences in vaccination policies. Countries with higher levels of vaccine distribution (including Canada) generally recommend that all persons 65 years of age and older be vaccinated, whereas countries with low levels recommend vaccine only for persons with recognized high risk conditions. Other differences between countries such as the structure of health insurance (ie, who pays for vaccination) seem to be less important, although within individual countries changes in payment mechanisms have often been followed by increased vaccination. One of the clearest lessons that can be drawn from experience in these countries is that large changes in vaccine distribution have usually followed policy decisions made by just a few health officials.

Investigators are also beginning to examine variations in influenza vaccination rates among individual 
TABLE 2

Comparative advantage of hospital-based influenza vaccination in preventing hospital admissions and deaths with pneumonia and influenza in Manitoba in 1982-83*

\begin{tabular}{|c|c|c|c|c|c|c|}
\hline Outcome event & $\begin{array}{l}\text { Age group } \\
\text { (years) }\end{array}$ & \multicolumn{2}{|c|}{$\begin{array}{l}\text { Health care contact during } \\
\text { vaccination season (\%) }\end{array}$} & \multicolumn{3}{|c|}{$\begin{array}{l}\text { Number of persons to be vaccinated } \\
\text { to prevent one outcome event }\end{array}$} \\
\hline Hospital admission & $65-74$ & 78 & 39 & 601 & 148 & 4.1 \\
\hline \multirow[t]{2}{*}{ Hospital death } & $65-74$ & 77 & 62 & 1305 & 200 & 6.5 \\
\hline & $\geq 75$ & 90 & 66 & 243 & 66 & 3.7 \\
\hline
\end{tabular}

"Adapted from (12); The numbers of persons to be vaccinated are based on a case control study (14). The study showed that in 1982-83, influenza vaccination was approximately $30 \%$ effective in preventing hospital admissions and approximately $60 \%$ effective in preventing hospital deaths for pneumonia and influenza due to all causes during the 12-week influenza outbreak period

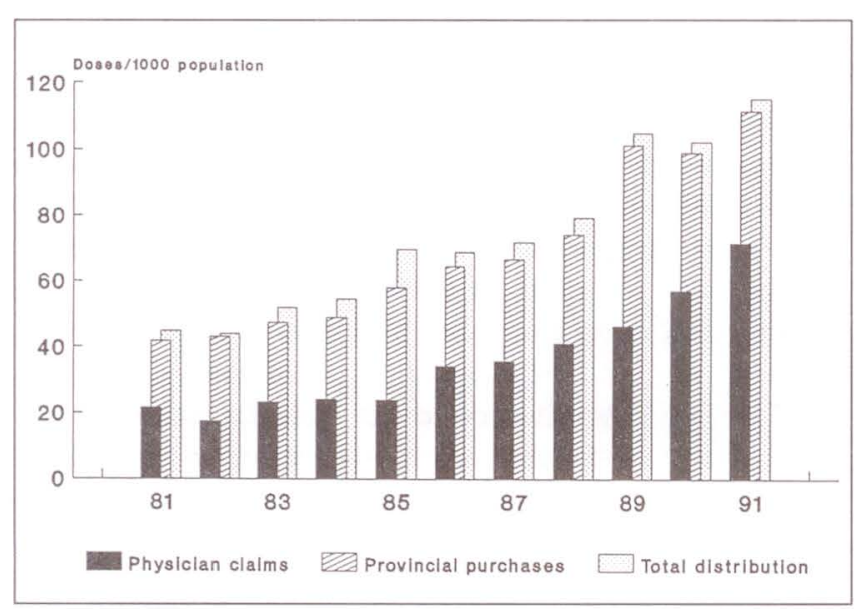

Figure 3) Influenza vaccine distribution, provincial vaccine purchases and physician claims for influenza vaccination in Manitoba, 1981-91

physicians, ie, immunization practice at the microepidemiological level. For example, in 1991 there was an almost ninefold variation in per capita vaccine use by general practitioners in Wales ( $\mathrm{J}$ Watkins, personal communication). On a larger scale, Andre Wajda, Pat Nicol, Leslie Roos and I recently reported on the vaccination practices of office-based physicians in Manitoba during the fall vaccination season in 1982. This study used the administrative database for all health care services in the province (12). All persons were stratified hierarchically into three mutually exclusive groups according to their patterns of health care during the vaccination season: hospital discharge with or without ambulatory care visits; ambulatory care visits only; and no health care contact. The findings were striking. Compared with persons who made only ambulatory care visits, those who were discharged from hospital during the vaccination season were seven to 10 times more likely to be readmitted a few months later with influenza-associated illness, and 15 to 20 times more likely to die. Yet discharged patients were less than half as likely to have been vaccinated. Among elderly patients, those discharged from hospital during the vaccination season accounted for only $8 \%$ of the total elderly population, yet they were responsible for 40 to $45 \%$ of those who were hospitalized and almost two-thirds of those who died of influenza-associated illness a few months later (Table 2). Compared with vaccinating persons with any health care contact, hospital-based influenza vaccination would have been three to four times more effective in preventing influenza-associated $\mathrm{P}+\mathrm{I}$ hospital admissions, and four to six times more effective in preventing $\mathrm{P}+\mathrm{I}$ hospital deaths. These epidemiological findings strongly support hospitalbased influenza vaccination, a strategy first proposed 10 years ago (13).

The evaluation of influenza vaccination practices in Manitoba emphasizes the need for a more detailed understanding of how vaccination recommendations are being implemented. Studies that examine the Manitoba experience in more recent years are planned. Similar studies should be undertaken in other provinces. They could provide either the assurance that influenza vaccine is reaching those who need it, or the basis for correcting a vaccine delivery system that is failing to vaccinate patients at greatest risk.

\section{DOCUMENT ALL INFLUENZA VACCINATIONS IN ADMINISTRATIVE DATABASES}

The findings from the Manitoba Influenza Study illustrate some of the many advantages of having computerized information on influenza vaccination available for research. Currently, I know of no other Canadian province (nor of any other developed country for that matter) with a population-based health care database such as that in Manitoba. This administrative database captures all claims for influenza vaccination given by physicians and links this information with several other data sets: a population registry; all physician claims for ambulatory care visits; all nursing home admissions; all hospital discharges by diagnosis; and a mortality registry. In recent years there has been a steady growth in influenza vaccine distribution and in physician claims for vaccination in Manitoba (Figure 3). As recently as 1991, physician claims accounted for $62 \%$ of all doses of influenza vaccine distributed in the province. Most of the remaining doses were probably used in nursing homes (where vaccination does not 
result in a physician claim), although some vaccine was probably given in retirement homes by public health nurses (particularly in northern Manitoba), by salaried physicians who did not submit claims, or was not used. Unfortunately, little is known about what happens to the influenza vaccine that is not accounted for by physician claims, and more information on this is needed.

The usefulness of the Manitoba database for research has been shown not only in the study of vaccination practices, but in a more recent evaluation of the clinical effectiveness of vaccination (14). Case control studies of influenza A $\left(\mathrm{H}_{3} \mathrm{~N}_{2}\right)$ outbreaks in 1982-83 and 1985-86 have shown that vaccination was 30 to $40 \%$ effective in preventing $\mathrm{P}+\mathrm{I}$ hospital admissions, 25 to $30 \%$ effective in preventing hospital admissions with all respiratory conditions, and 30\% effective in preventing death from all causes.

These measures of clinical effectiveness applied to all outcome events during broadly defined (10- to 12-week) outbreak periods. They included all such events regardless of microbial etiology; ie, only some of them were associated with influenza virus infection. Thus, if vaccination was 30\% effective in preventing all hospital admissions with $\mathrm{P}+\mathrm{I}$, and if only $50 \%$ of these events were caused by influenza virus infection, then the true efficacy of the vaccine was 60\%. Equally importantly, the Manitoba findings showed that vaccination did not lead to replacement morbidity or mortality; ie, influenza-associated hospital admissions that were prevented were not replaced by admissions caused by other microbial agents. From a health policy perspective this is probably the study's most important finding. It shows that influenza vaccination has clear health benefits for the population.

Administrative databases such as the one in Manitoba can be used in other ways. The methods developed in the case control studies can be used to evaluate the effectiveness of influenza vaccination each year. Doing so would add a new dimension to the WHO influenza program. In addition, the database makes it possible to ask questions regarding vaccine safety such as, for example, whether there is an association between vaccination and Guillain-Barré syndrome. If other provinces were to develop administrative databases similar to the one in Manitoba, Canadians would have a much greater capacity to assess the impact of influenza on society and to evaluate their programs for its prevention.

\section{DO THE SAME FOR PNEUMOCOCCAL VACCINATION}

Given their success with influenza vaccination, it is both surprising and disappointing that Canadians have essentially ignored pneumococcal vaccine. In this they are not alone; except for the United States, all developed countries use very little pneumococcal vaccine.
TABLE 3

Major target populations for influenza and pneumococcal vaccination and vaccine distribution in Canada, 1991

\begin{tabular}{|c|c|c|c|c|}
\hline \multirow[b]{2}{*}{ Vaccine } & \multicolumn{2}{|c|}{ Major target population } & \multirow[b]{2}{*}{$\begin{array}{l}\text { Total doses } \\
\text { distributed }^{\dagger}\end{array}$} & \multirow[b]{2}{*}{$\begin{array}{c}\text { Potential } \\
\text { coverage }\end{array}$} \\
\hline & $\begin{array}{l}\text { Age group } \\
\text { (years) }\end{array}$ & Number* & & \\
\hline Influenza & $\geq 65$ & $3,140,100$ & $3,511,047$ & $100 \%$ \\
\hline $\begin{array}{r}\text { Pneumo- } \\
\text { coccal }\end{array}$ & 65 & 222,000 & 33,085 & $15 \%$ \\
\hline
\end{tabular}

"Resident population June 1, 1991; 'Unpublished observations by the author

Yet the morbidity and mortality attributable to pneumococcal disease is, if anything, greater than that caused by influenza (7). Furthermore, the clinical effectiveness of pneumococcal vaccination has been firmly established in case control studies. Until the recent publication of case control studies of influenza vaccination $(14,15)$, the evidence for the effectiveness of pneumococcal vaccination was better than that for influenza vaccination. Thus, it is striking that Canadian physicians have used only one of the two vaccines that can be used effectively to prevent serious respiratory infections in older and other high risk patients. It would be unthinkable for the same physicians to use only one drug to prevent the occurrence of pulmonary edema in patients diagnosed as having congestive heart failure.

The extent of the underuse of pneumococcal vaccine in Canada is suggested by the scenarios shown in Table 3. Let's assume that the major target group for influenza vaccination is all persons 65 years of age and older (approximately 85\% of the serious morbidity and mortality affects the elderly [1]). In 1991, influenza vaccine distribution exceeded by almost 400,000 doses the total elderly population. Influenza vaccination rates among the elderly are nowhere near 100\%; they are somewhere between 40 and 60\%. Next, let's assume that the major target population for pneumococcal vaccination is all elderly persons who have reached their 65 th birthday. The distribution of pneumococcal vaccine in 1991 was sufficient to cover only $15 \%$ of all 65-year-old Canadians.

During the past two years, pneumococcal vaccine distribution in Canada has shown a modest increase, and it should increase even more in coming years. For this reason, efforts should be undertaken now to measure the impact of pneumococcal infections on mortality, hospitalization and costs to the Canadian health care system. Methods must also be developed to monitor pneumococcal vaccination at the macro- and microepidemiological levels. Mechanisms that accurately document all physician claims for pneumococcal vaccination must be established before vaccine use becomes widespread. If this can be done, administrative databases can be used to assess pneumococcal vaccination practices and clinical effectiveness. Eventually, such 
databases should provide us with an accurate measure of the clinical effectiveness of influenza and pneumococcal vaccination combined.

\section{CONCLUSIONS}

As a non-Canadian who has observed immunization practices in Canada for several years, I have come to admire the straightforward, well coordinated and increasingly effective systems for delivering influenza vaccine to patients in this country. While some of the growth in vaccine delivery may be due to a general increase in the volume and intensity of services provided

ACKNOWLEDGEMENTS: Thanks to Leslie L Roos, Andre Wajda, $J$ Patrick Nicol and the staff of the Manitoba Centre for Health Policy and Evaluation for their many contributions to the Manitoba Influenza Study; Connaught Laboratories, Ltd and IAF BioVac, Inc for information on influenza vaccine distribution in Canada; and to Deanna Brown for preparing the manuscript.

\section{REFERENCES}

1. Fedson DS. The influenza vaccination demonstration project: An expanded policy goal. Infect Control Hosp Epidemiol 1990;11:357-61.

2. Liu K, Kendal AP. Impact of influenza epidemics on mortality in the United States from October 1972 to May 1985. Am J Public Health 1987;77:712-6.

3. Blackwelder WC, Alling DW, Stuart-Harris CH. Association of excess mortality from chronic nonspecific lung disease with epidemics of influenza. Am Rev Respir Dis 1982;125:511-6.

4. Perrotta DM, Decker M, Glezen WP. Acute respiratory disease hospitalizations as a measure of impact of epidemic influenza. Am J Epidemiol 1985: 122:468-76.

5. Barker WH. Excess pneumonia and influenza associated hospitalization during influenza epidemics in the United States, 1970-78. Am J Public Health 1986;76:761-5.

6. Schoenbaum SC. Economic impact of influenza. The individual's perspective. Am J Med 1987:82(Suppl 6A):26-30.

7. Fedson DS. Clinical practice and public policy for influenza and pneumococcal vaccination of the elderly. by Canadian physicians (16), I believe vaccine delivery levels also reflect broader features of Canadian health care that many Americans find increasingly attractive.

The structure of Canada's provincial health care systems and the administrative databases that support them in each province should be recognized as providing resources for research on influenza and pneumococcal vaccination that cannot be found in any other country. For this reason, Canadians have a unique opportunity and an obligation to contribute to our understanding of the impact of influenza and pneumococcal infections and our programs for their prevention.

Clin Geriatr Med 1992;8:183-99.

8. Riddiough MA, Sisk JE, Bell JC. Influenza vaccination: Cost effectiveness and public policy. JAMA 1983;249:3189-95.

9. Helliwell BE, Drummond MF. The costs and benefits of preventing influenza in Ontario's elderly. Can J Public Health 1988;79:175-80.

10. Ghendon Y. Influenza surveillance. Bull World Health Organ 1991;69:509-15.

11. Fedson DS. Overview of national approaches to influenza vaccination. In: Hannoun C, Kendal AP, Klenk HD, Ruben FL, eds. Options for the Control of Influenza II. Amsterdam: Excerpta Medica, 1993:39-43.

12. Fedson DS, Wajda A, Nicol JP, Roos LL. Disparity between influenza vaccination rates and risks for influenza-associated hospital discharge and death in Manitoba in 1982-1983. Ann Intern Med 1992; 116:550-5.

13. Fedson DS, Kessler HA. A hospital-based influenza immunization program, 1977-78. Am J Public Health 1983;73:442-5.

14. Fedson DS. Linked record studies of influenza and its control. In: Hannoun C, Kendal AP, Klenk HD, Ruben FL, eds. Options for the Control of Influenza II. Amsterdam: Excerpta Medica, 1993:393-6.

15. Foster DA, Talsma A, Furamoto-Dawson A, et al. Influenza vaccine effectiveness in preventing hospitalization for pneumonia in the elderly. Am J Epidemiol 1992;136:296-307.

16. Fuchs VR, Hahn JS. How does Canada do it? A comparison of expenditures for physicians' services in the United States and Canada. N Engl J Med 1990;323:884-90. 


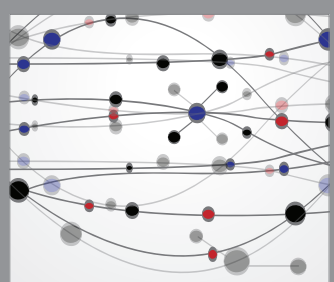

The Scientific World Journal
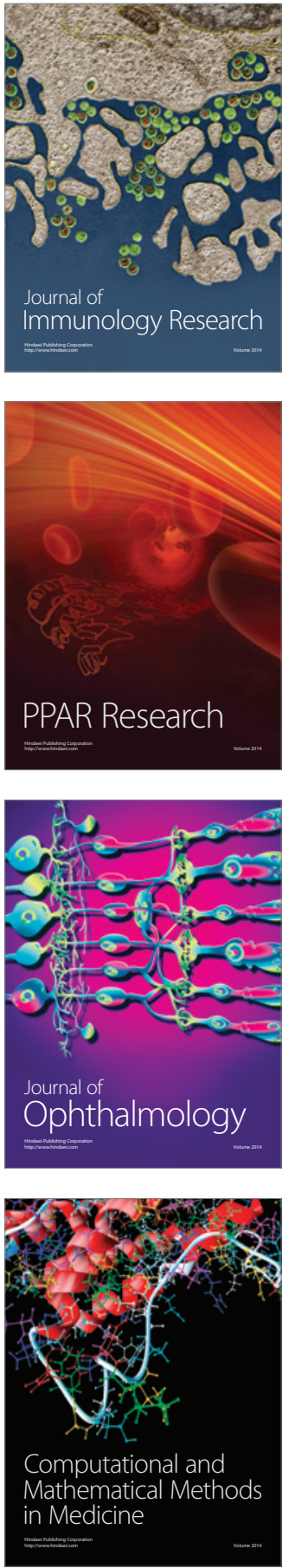

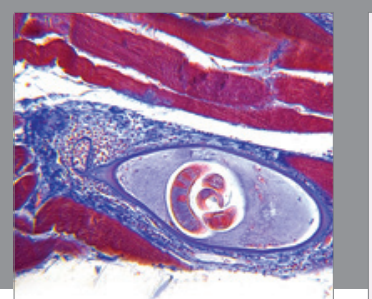

Gastroenterology Research and Practice

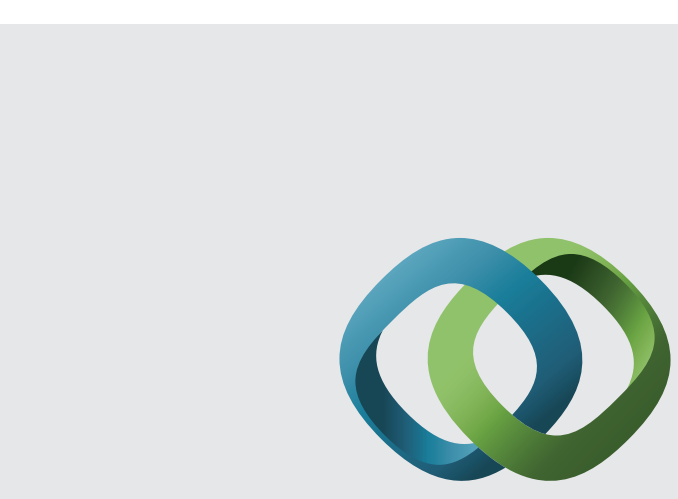

\section{Hindawi}

Submit your manuscripts at

http://www.hindawi.com
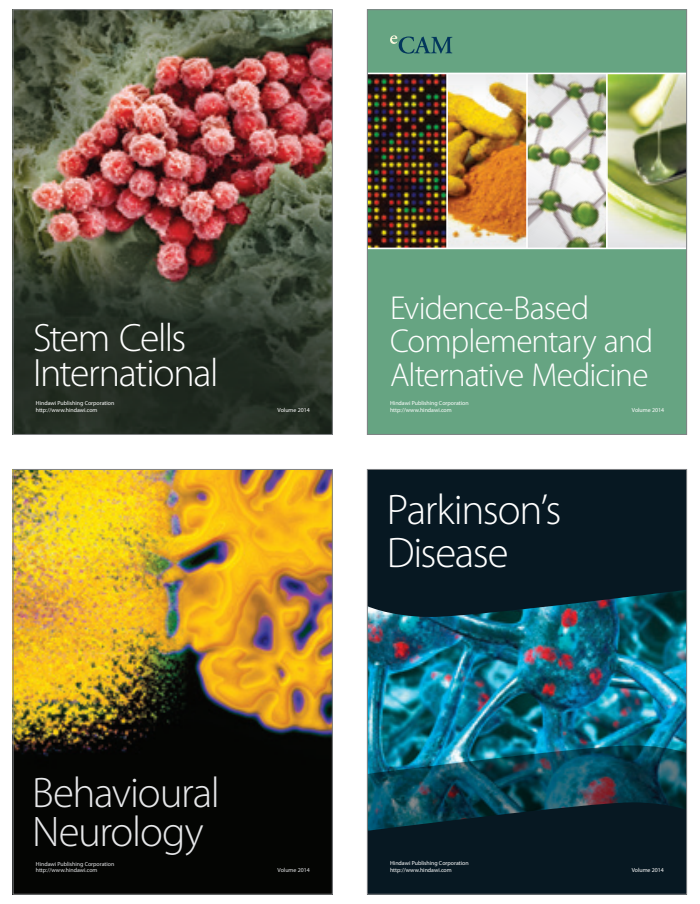
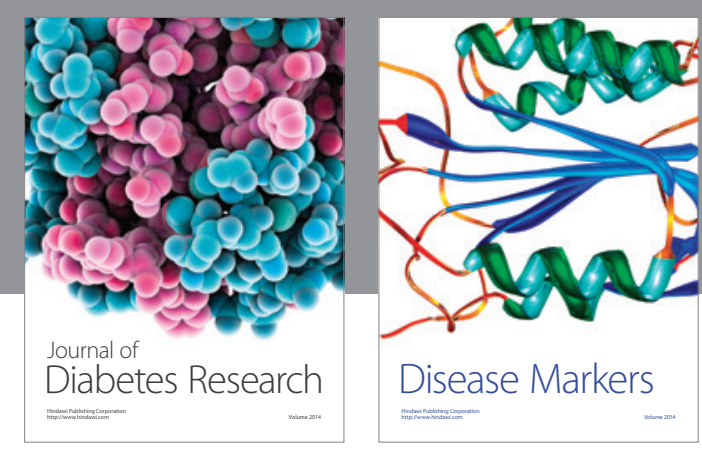

Disease Markers
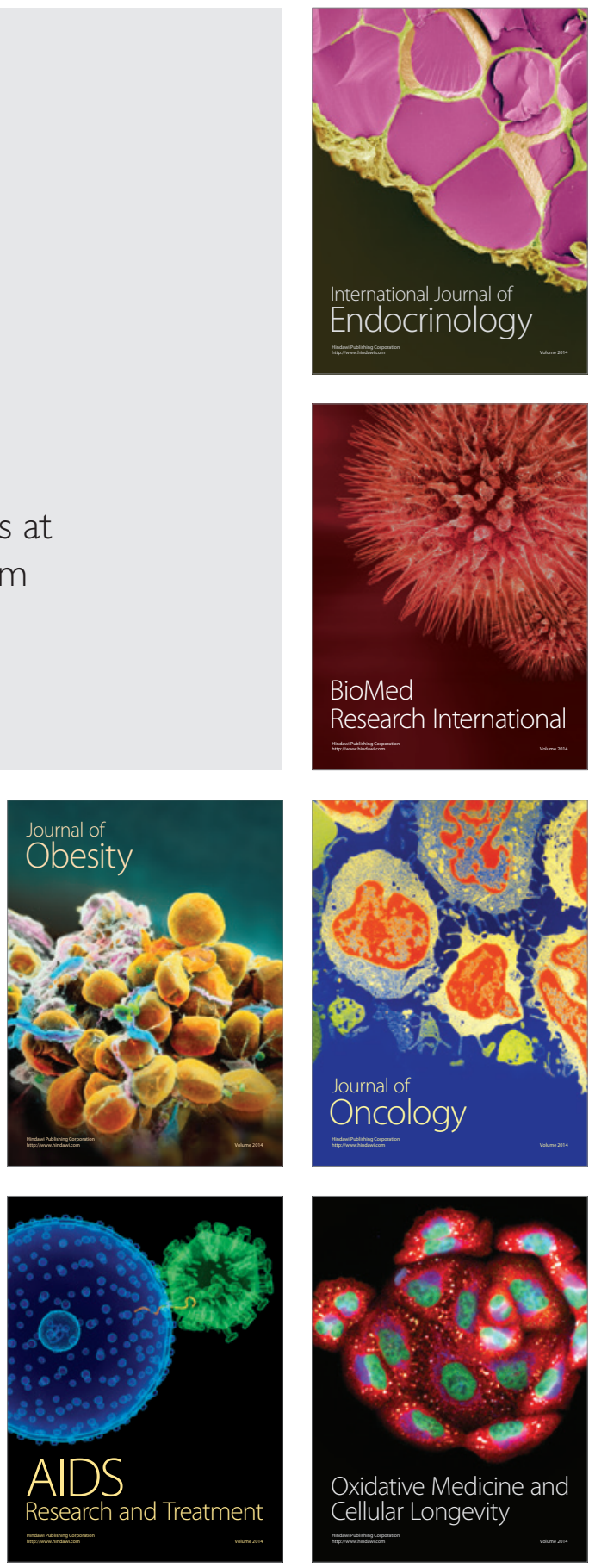